\title{
The Restorative Effect of the Environment on Organizational Cynicism and Work Engagement
}

\author{
Diego Bellini' ${ }^{1}$ Tiziana Ramaci², Marino Bonaiuto ${ }^{3}$ \\ ${ }^{1}$ Department of Philosophy, Education and Psychology, University of Verona, Verona, Italy \\ ${ }^{2}$ Department of Human and Social Sciences, Kore University, Enna, Italy \\ ${ }^{3}$ Department of Psychology of Developmental and Socialization Processes and CIRPA Centre for \\ Inter-University Research in Environmental Psychology, Sapienza University of Rome, Rome, Italy \\ Email: diego.bellini@univr.it, tiziana.ramaci@unikore.it, marino.bonaiuto@uniroma1.it
}

Received 8 July 2015; accepted 15 September 2015; published 18 September 2015

Copyright (C) 2015 by authors and Scientific Research Publishing Inc.

This work is licensed under the Creative Commons Attribution International License (CC BY).

http://creativecommons.org/licenses/by/4.0/

(c) $\underset{\mathrm{EY}}{\mathrm{B}}$ Open Access

\section{Abstract}

The aim of this study is to explore the relationship between restorativeness, work engagement and organizational cynicism. A positive effect of restorativeness on work engagement and a negative effect on organizational cynicism are hypothesized. A self-report questionnaire was filled out by 247 employees. Results of hierarchical linear regression supported a positive effect of restorativeness in reducing both organizational cynicism and in fostering work engagement. The original contribution of this research is the analysis of the multivariate relationship between restorativeness (which is a relevant construct in environmental psychology) and relevant constructs deriving from the work and organizational psychology field (i.e., work engagement and cynicism in the workplace).

\section{Keywords}

Restorativeness, Environment, Cynicism, Work Engagement, Well-Being

\section{Introduction}

Many studies, [1] [2], have revealed that job resources, i.e. physical, psychological and organizational aspects of the job, are involved in achieving work goals and reducing job demands, e.g. work overload, emotional and physical demands [3], and that they are predictors of positive outcome such as work engagement [4]. Conversely, certain job demands can have a profound influence on job stress and burnout [5] and on work-related outcomes, 
e.g. work engagement and emotional exhaustion [6] [7]. Further, there is some evidence supporting a negative relationship between job resources and burnout, because a large pool of job resources may help employees to cope with job demands and protect them from the strains of resource depletion [4] [8] [9]. Nevertheless, the physical aspect of the job and specifically the restorative properties of the environment in the workplace and its influence on positive and negative work related outcomes substantially have not been considered, particularly in their interplay with some possibly relevant organizational psychology constructs ${ }^{1}$. Research, as described in the following paragraph, has proven that restorative qualities of the environment are able to decrease perceived job stress [11], mental fatigue-related-illness, and depletion of energy through the restoration of direct attention. To explore the restoration properties in the workplace, the rationale is drawn from Attention Restoration Theory (ART) [12]-[14] and Stress Reduction Theory (SRT) [15] [16]. Furthermore, within such a general theoretical framework-coupling, between organizational psychology and environmental psychology, the main hypotheses here considered are derived from the Job Demands-Resources model (JD-R) [3]. Thus, the present research tests the positive influence of restorativeness qualities of the environment (measured by the construct of restorativeness) on Work Engagement; and a corresponding negative effect of organizational cynicism [17] considered as the core dimension of job burnout [18]. Generally, the question whether restorativeness can positively influence work engagement in the organization has not been studied so far. In the literature, just one study showed the positive effect of restorativeness on work engagement [19]. Furthermore, in the literature, the negative effect of restorativeness on organizational cynicism had not been addressed. The following paragraphs describe these relationships more in depth, considering some variables that could impact on employees' work engagement and organizational cynicism too (i.e., sample characteristics in terms of as socio-demographic variables).

\subsection{Restorativeness within the Workplace}

The concept of "restorative environments" [20] refers to those elements of places, which allow people to distract, to relax, and to distance themselves from ordinary aspects of life and workplace ${ }^{2}$. To understand this process, ART [14] explains what is being fatigued or depleted, and suggests how this element or resource can be restored. In particular, mental fatigue occurs after prolonged and intense use: the capacity to direct attention is reduced and the capacity to ward off distractions diminishes [21]. Fascinating qualities [22], such as natural settings, attract involuntary attention (a kind of effortless attention) and thus their directed attention (a kind of effortful attention) can rest and be restored [13]. Through this process, described by SRT [15] environment supports restoration, or stress recovery, as a kind of prolonged aesthetic response to the environment. However, within the workplace the interaction among work characteristics (job demands and job resources) plays a pivotal role to promote positive or negative effects on employees [4]. The physical and social environmental conditions of the place put demands on individuals that exceed their capabilities, thus creating a lack of balance [23], and then stress. Conversely, restorativeness has psychologically restorative effects on people and these positive effects are also associated with nature/green [24]. The physical environment "restores" the organism, this provides psychological benefits in terms of attention restoration, stress reduction [25], and well-being. Anyhow, this research focused particularly on the restorativeness process and experience of the environment, not directly considering the "green" in the workplace, but the perceived restorative quality of the environment which is strictly connected with natural elements and the built elements, and-as described above-on environmental fascination qualities that are able to reduce stress. The physical restorative process, reducing perceived job stress and increasing job satisfaction [11] [26], is also involved in achieving work goals and reducing job demands. Thus, as mentioned in the introduction, in this study restorativeness is considered as a job resource or a physical and psychological aspect of the job that is involved in achieving work goals and reducing job demands [3]. In view of these considerations, this study explores the construct of restorativeness in its relationship with some psychological-sociological dimensions: namely, work engagement and organizational cynicism. As argued in the following paragraphs, these variables have a central role to enhance job-stress and well-being.

\subsection{Cynicism and Restorativeness}

In a review article, Dean, Brandes and Dharwadkar (1998) [17] define employee cynicism as "a negative atti-

\footnotetext{
${ }^{1}$ More specifically, restoration is defined as "the process of renewing physical, psychological and social capabilities diminished in ongoing efforts to meet adaptive demands" [10].

${ }^{2}$ According to Kaplan \& Kaplan (1989) [4], restorativeness refers to the capacity of the environments "to offer a concrete and available means of reducing suffering and enhancing effectiveness" (p. 176).
} 
tude towards one's employing organization, comprising three dimensions: a belief that the organization lacks integrity; negative affect toward the organization; and tendencies to disparaging and critical behavior toward the organization that are consistent with these beliefs and affect: it is a variable state, which may change over time as the employee faces new experiences" (p. 345). Organizational cynicism has been shown to be "susceptible to change by exposure to factors in the environment" [27]. Research has reported a positive correlation between emotional exhaustion and organizational cynicism [28]. Cynicism represents the dimension of burnout [29] as a means of creating defensive cognitive distance, and it is regarded as a defensive coping response to exhaustion [30]. Burnout is traditionally characterized as a syndrome of exhaustion, cynicism, and lack of efficacy experienced by employees [29] [31]. The research examining organizational cynicism suggests that cynicism has important and prolonged negative effects on individual and organizational effectiveness such as, disengagement and performance [32]. Thus, since researchers underline a central role of the environment in reducing stress and in promoting employees' well-being, it is important to study the role of restorativeness, i.e. a positive feature of people-environment relation, in the relationship with organizational cynicism and work engagement within a specific context.

\subsection{Work Engagement}

Engagement has been defined as a positive, fulfilling, work-related state of mind that is characterized by vigor, dedication, and absorption [33]. Not only work engagement is a positive experience in itself, but it also seems related to good health, positive work outcomes, commitment and perceptions of self-efficacy and work performance [34], such as lower burn-out [34], lower turn-over intention [35], lower work stress [36], and well-being [35]. As described in the following paragraph, the framework of the JD-R model provides a useful lens for understanding the relationship among restorativeness (here considered as a job resource), organizational cynicism (which is considered a dimension of burnout), and work engagement (which is an outcome of job resources).

\subsection{The Job Demands-Resources Model (JD-R) and Restorativeness: A Motivational Process}

The basic premise of the JD-R model is that, even though every occupation may have its own set of risk factors related to job strain, those risk factors can either be categorized as job demands or job resources. In this model, demands contribute to develop strain, exhaust employees' mental and physical resources ${ }^{3}$. This process can lead to a depletion of energy [4]. The JD-R model proposes that job demands and resources play a role in the development of burnout and engagement [4] [8]. Many studies [1] have confirmed these hypotheses, by showing that high job demands lead to employees' health problems whereas the presence of job resources facilitate employees' motivation. Job strain is caused by chronic job demands (e.g. emotional exhaustion) and by depletion of resources. According to Demerouti, et al. [3], job resources contribute to motivation and are viewed as having a strong motivational potential [37], which lead to high work engagement, low cynicism and high performance. Within the JD-R model, job demands may evoke an health impairing process of energy-depletion leading to burnout and health problems [38], whereas job resources induce a motivational process leading to high work engagement [39], and excellent performance [40]. This effect is consistent with the Conservation of Resources theory (COR) [41] [42], which assumes that people strive to obtain, build, conserve, and protect the quality and quantity of their resources. The existence of resources tends to generate other resources, which lead to well-being and positive outcomes. When the organization does not provide employees with job resources, the consequence is reduced motivation and commitment [43]. Furthermore, it should be noted that environmental stress can diminish the motivation toward a given task [44]. Conversely, the restorative environment, reducing environmental stress, can promote resource recovery from job demands. Thus, the restorative quality of the environment can support this motivational process at work. To sum up, a lot of cross-sectional studies using the JD-R model [2] confirms that changes in demands and resources predict future burnout and work engagement. A longitudinal study [40], concluded that the decrease of job resources predicted burnout. There is some evidence

\footnotetext{
${ }^{3}$ According to Demerouti et al. [3]: job demands (e.g., work overload, emotional and physical demands) "represent those aspects of the job that require prolonged physical and psychological effort and that are linked to physiological and psychological costs" (p. 501); job resources "represent characteristics of the job and are defined as "those physical, psychological, social or organizational aspects of the job that are functional achieving work goals, reducing job demands and their associated physiological and psychological costs, and, finally, stimulating personal growth, learning, and development" (p. 501).
} 
supporting a negative relationship between job resources and burnout, because a large pool of job resources may help employees to cope with job demands and may protect them from the strains of resource depletion [9]. In other words, working in a demanding job and having few job resources is associated with burnout and then with organizational cynicism.

\subsection{Objective and Hypotheses}

We expect that restorativeness (which is considered as a proxy variable for environmental conditions) as a people-environment relationship resource, on one hand helps to reduce cynicism, and the other hand aids to promote engagement.To test these relationships some socio-demographic variables like gender, age and kind of contract have been controlled for.

Hypothesis 1: Restorativeness will be positively associated with work engagement.

Hypothesis 2: Restorativeness will be negatively associated with organizational cynicism (cognitive, motivational and behavioral dimensions).

\section{Materials and Methods}

\subsection{Procedure and Participants}

We handed out the questionnaires used in the current study to the employees, who returned them to the researchers. Participants (246) work in an office within one of seven different sectors: agriculture, trade, public administration, education, human resources, service, and health and personal care. All participants were invited to participate on a voluntary basis and they were informed about the aim of the study. The respondents were asked not to mention their name or the name of their organization anywhere on the questionnaire to ensure confidentiality. Participants were Italian employees (44.1\% males, 55.9\% females), age ranging from 23 to 66 years $(M=43$; $S D=9.77)$. The respondents are for the most part employees $(51 \%)$, only $9.5 \%$ are in managerial position; the others are blue collars (15.5\%) and with unspecified role (24\%). In general, 25.2\% of workers have 5 or less years of experience, between 5 and 15 years are 34.9\%, between 16 and 25 years are $29.4 \%$, more the 25 years up to 35 are $10.5 \%$. On average workers have a good experience (14 years at work; SD $=9.31$ ) but with a large range from few months of work up to 35 years. They work on average for 7 hours per day $(\mathrm{SD}=1.97)$.

The following Table 1 shows other demographic characteristics of the sample.

\subsection{Instruments}

Participants filled in a self-report questionnaire including the following measures.

\subsection{Dependent Variables}

Work Engagement: it was measured by using the Utrecht Work Engagement Scale (UWES) [33]. The measures consisted of a 9-item scale, and it was validate in Italy by Balducci, Fraccaroli and Schaufeli (2010) [45]. Respondents rated their level of agreement with the survey statements on a 7-point Likert type scale with options from never (=0) to every day (=6). Two sample items from the measure are: "At my work, I feel bursting with energy"; "I get carried away when I am working (see Appendix 1).

Organizational Cynicism: it was measured by using the Organizational Cynicism Scale (OCS) [46]. This scale was validated in Italy by Bobbio, Manganelli and Rattazzi (2006) [47] and consisted of a 14-item scale. Respondents rated their level of agreement with the survey statements on a 5-point Likert type scale with options from never (=1) to always (=5). Two sample items from the measure are "I believe that my company says one thing and does another"; "When I think about my organization, I feel a sense of anxiety" (see Appendix 2).

Table 1. Other demographic characteristics of the sample.

\begin{tabular}{cc}
\hline \multicolumn{1}{c}{ Demographic variables } & Percentage of workers \\
\hline Workers that work with people & $32.5 \%$ \\
Workers with permanent contract & $61 \%$ \\
\hline
\end{tabular}




\subsection{Dependent Variables}

Perceived Restorativeness Scale (PRS) [48]: it was used in a versions with a 16-item scale extracted from the Italian PRS [49]. Each item was rated on a 7-point response scale, from strongly disagree $(=0)$ to strongly agree $(=6)$. Two sample items from the measure are: "It is an escape experience"; "I have a sense of oneness with this setting” (see Appendix 3).

\subsection{Socio-Demographics and Control Variables}

The last part of the questionnaire contains a section with socio-demographic variables. In particular, participants were asked, on a categorical scale with different points, to indicate: gender (operationalized as a dummy variable, 1 = male and 2 = female), age (measured in years), type of contract (four categories: permanent contract, temporary contract, other forms of contract).

\subsection{Data Analyses}

At a preliminary stage, before testing hypotheses with Hierarchical Regression Analyses, Confirmatory Factor Analyses (CFAs) as implemented by AMOS [50]. This analysis deal with potential concerns about common method variance. CFAs were performed in order to assess the measurement model and to verify both the structure of the constructs before testing the hypothesized relationships among them. CFAs allow verification of convergent and discriminant construct validity [51].

\section{Results ${ }^{4}$}

\subsection{Preliminary Analyses: CFAs}

Work Engagement. CFA, with an ADF (asymptotically distribution free) methods, supported the one factor structure, $\chi^{2}=13.490 p=0.142, \mathrm{df}=9, \chi^{2} / \mathrm{df}=1.499$, CFI $=0.944$, TLI $=0.870$, RMSEA $=0.045$. The scale was reliable and Cronbach's alpha coefficient was 0.91 .

Organizational Cynicism. CFA with maximum likelihood estimation of parameters, supported the three factor structure, $\chi^{2}=32.328 p=0.054, \mathrm{df}=21, \chi^{2} / \mathrm{df}=1.539$, CFI $=0.990$, TLI $=0.982$, RMSEA $=0.047$. Cronbach's alphas were respectively 0.88 for cognitive dimension, for the emotional dimension was 0.90 and for the behavioral dimension was 0.75 .

Perceived Restorativeness. CFA with maximum likelihood estimation of parameters, confirmed the two factor structure, $\chi^{2}=78.818 . p=0.001, \mathrm{df}=11, \chi^{2} / \mathrm{df}=2.580$, CFI $=0.965$, TLI $=0.946$, RMSEA $=0.080$. The two factors, namely "fascination" and "being away from routine", were highly correlated $(r=0.84)$, then one factor was considered in the following analysis. Cronbach's alpha coefficients were: 0.90 for the "fascination" dimensions and 0.76 for the "being away from routine" dimension.

\subsection{Zero-Order Correlation}

Pearson correlations were performed to discern any effect of demographic variables on work engagement and on organizational cynicism. As presented in Table 2, age is positively and significantly correlated with all three dimension of organizational cynicism and Kind of contract is negatively and significantly correlated with all three dimension of organizational cynicism. About the assumptions between the constructs, restorativeness is positively related to work engagement and negatively related to all three dimensions of organizational cynicism.

\subsection{Hypotheses Testing Analyses}

Preliminarily data were considered for hierarchical regression analyses on organizational cynicism and on work engagement. Every assumption was respected for organizational cynicism. Also formula $X=\log (K-X)$ to resolve problem of skewness in work engagement variable was used [52]. Three potential outliers in work engagement variable with standardized residual greater than 3 in absolute value were eliminated [53]. As suggested by Tabanchnick and Fidell (2012) [54], other two multivariate outliers who did not respect assumption of Mahalanobis Distance $(\chi=20.51 p<0.001)$ were excluded.

${ }^{4}$ Data analysis was performed by using SPSS and AMOS statistical package. 
Table 2. Descriptive statistics and correlations $(\mathrm{N}=246)$.

\begin{tabular}{|c|c|c|c|c|c|c|c|c|c|}
\hline & $M$ & $S D$ & 1 & 2 & 3 & 4 & 5 & 6 & 7 \\
\hline 1. Age & 43 & 9.79 & 1 & & & & & & \\
\hline $\begin{array}{l}\text { 2. Gender }(1=\mathrm{M}, 2=\mathrm{F}) \\
\text { in percentage. }\end{array}$ & $\begin{array}{l}44.1 \text { males } \\
55.9 \text { females }\end{array}$ & N.R & -0.051 & 1 & & & & & \\
\hline $\begin{array}{l}\text { 3. Kind of contract } \\
(1 \text { = permanent, } \\
2 \text { = temporary }) \text { in percentage }\end{array}$ & $\begin{array}{l}61 \%=1 \\
39 \%=2\end{array}$ & N.R & $-0.200^{* *}$ & 0.010 & 1 & & & & \\
\hline 4. Restorativeness & 3.26 & 1.24 & -0.121 & 0.041 & $0.216^{* *}$ & 1 & & & \\
\hline 5. Cynicism/Cogn. & 2.94 & 1.12 & $0.232^{* *}$ & -0.081 & $-0.286^{* *}$ & $-0.328^{* *}$ & 1 & & \\
\hline 6. Cynicism/Emot. & 2.33 & 1.06 & $0.204^{* *}$ & 0.010 & $-0.137^{* *}$ & $-0.307^{* *}$ & $0.465^{* *}$ & 1 & \\
\hline 7. Cynicism/Beh. & 2.03 & 0.882 & $0.223^{*}$ & -0.091 & $-0.212^{* *}$ & $-0.244^{*}$ & $0.407^{* *}$ & $0.501^{* *}$ & 1 \\
\hline 8. Work Engagement & 4.80 & 1.30 & 0.043 & 0.054 & 0.121 & $477^{* *}$ & $-0.311^{* *}$ & $-0.366^{* *}$ & $-0.313^{* *}$ \\
\hline
\end{tabular}

\subsection{Linear Hierarchical Regression Analysis}

Linear hierarchical regression analysis has been conducted in two steps. In the first step, demographic characteristics were analyzed in the correlation matrix to control for possible confounding effects. Results, as reported in Table 3, indicated the effects of the demographic variables on work engagement and on organizational cynicism. In particular, age had positive effect on all three dimensions of cynicism: cognitive dimension ( $b=179 p<0.05)$; emotional dimension $(b=185 p<0.05)$; behavioral dimension $(b=185 p<0.05)$. Kind of contract had negative effect on cognitive $(b=-242)$ and behavioral organizational cynicism dimension $(b=-171)$. In the first step the model 1 with socio-demographic variables on work engagement had not acceptable fit $(F>0.05)$. Results in the second step showed a positive effect of restorativeness on work engagement ( $b=0.475 p<0.001)$. As shown in Table 3, Hypothesis 1 was confirmed. The second hypothesis confirmed the negative relations between restorativeness on cognitive (beta $=-275 p<0.05$ ), emotional (beta $=-271 ; p<0.05$ ) and behavioural (beta $=-196 ; p$ $<0.001$ ) dimensions of organizational cynicism, as shown in Table 3. Hypothesis 2 was confirmed.

\section{Discussion, Conclusion and Limitations}

This research provides a contribution to understand the relationship between perceived environmental conditions (which are measured by using the construct of restorativeness), organizational cynicism and work engagement. For the first time within the JD-R model [4] literature, this study tested the relationship between restorativeness and organizational cynicism. Bellini, Fornara and Bonaiuto (2015) [19], using the JD-R model, showed the positive effect of restorativeness on work engagement. Within this model, restorativeness is considered a job resource since it refers to physical and psychological aspects of the job that are involved in achieving work goals and reducing job demands [3]. Consistent with (H1), our findings here indicate a positive effect of restorativeness on work engagement. Research revealed that job resources are predictors of positive outcomes such as work engagement [4]. These findings point to the role of work environment as an employees' aid to recover from work stress and to motivate them to work. In fact, it has been proven that environmental stress can diminish the motivation towards a given task [44], on the contrary recovery from stress, through the restorative experience, it is able to reduce perceived job stress and to increase job satisfaction [11] [26]. In other words, when the organization provides employees a restorative environment (that is, job resources), the consequence is motivation and commitment [38]. Furthermore, restorativeness is able to reduce organizational cynicism (which is considered an integral dimension of burnout) within the organization (H2). With respect to this point, Schaufeli et al. [40], concluded that a decrease in job resources predicted burnout. The positive effect of restorativeness on cynicism is aligned with ART and SRT, the two main theories of restorativeness and the JR-D model. Thus, the restorative environment seems able to help people in replenishing or gaining internal resources within the workplace. More generally, in reducing their stress [15] [55] and in supporting their work behaviours, it can promote resource recovery from job demands. Probably these results mean that the environment is able to reduce the exhaustion of employees' energy resources and it may therefore prevent cynicism. In fact, stress fosters 
Table 3. Hierarchical regression of demographic variables, restorativeness on three dimensions of cynicism $(\mathrm{N}=246)$ and work engagement.

\begin{tabular}{|c|c|c|c|c|c|c|c|c|c|c|c|c|}
\hline & \multicolumn{3}{|c|}{ Cynicism Cognitive } & \multicolumn{3}{|c|}{ Cynicism Emotional } & \multicolumn{3}{|c|}{ Cynicism Behavioral } & \multicolumn{3}{|c|}{ Work Engagement } \\
\hline $\begin{array}{c}\text { Step 1: } \\
\text { Demographic } \\
\text { variables }\end{array}$ & $\beta$ & $t$ & $p$ & $\beta$ & $t$ & $p$ & $\beta$ & $t$ & $p$ & $\beta$ & $t$ & $p$ \\
\hline Age & 0.179 & 2.828 & $<0.05$ & 0.185 & 2.820 & $<0.05$ & 0.185 & 2.862 & $<0.05$ & 0.003 & 0.079 & n.s \\
\hline Gender & -0.080 & -1.291 & n.s & 0.028 & 0.437 & n.s & -0.073 & -1.153 & n.s & 0.060 & 0.067 & n.s \\
\hline Kind of contract & -0.242 & -3.815 & $<0.05$ & -0.100 & -1.533 & n.s & -0.171 & -2.658 & $<0.05$ & 0.023 & 0.164 & $<0.05$ \\
\hline \multicolumn{13}{|l|}{ Step 2} \\
\hline Age & 0.159 & 2.599 & $<0.05$ & 0.165 & 2.596 & $<0.05$ & 0.170 & 2.676 & $<0.05$ & 0.003 & 0.115 & n.s \\
\hline Gender & -0.066 & -1.107 & n.s & 0.042 & 0.675 & n.s & -0.063 & -1.012 & n.s & 0.053 & 0.043 & n.s \\
\hline Kind of contract & -0.181 & -2.895 & $<0.05$ & -0.040 & -0.623 & n.s & -0.128 & -1.971 & $<0.05$ & 0.021 & 0.059 & n.s \\
\hline Restorativeness & -0.275 & -4.456 & $<0.05$ & -0.271 & -4.224 & $<0.05$ & -0.196 & -3.049 & $<0.05$ & 0.002 & 0.475 & $<0.001$ \\
\hline Model1 R2 & \multicolumn{3}{|c|}{0.115} & \multicolumn{3}{|c|}{0.052} & \multicolumn{3}{|c|}{0.083} & \multicolumn{3}{|c|}{0.032} \\
\hline \multirow[t]{2}{*}{ Model1 adjusted $R 2$} & \multicolumn{3}{|c|}{0.104} & \multicolumn{3}{|c|}{0.040} & \multicolumn{3}{|c|}{0.071} & \multicolumn{3}{|c|}{0.019} \\
\hline & \multicolumn{3}{|c|}{$F(3.230)=10.008^{* *}$} & \multicolumn{3}{|c|}{$F(3.230)=4.210^{* *}$} & \multicolumn{3}{|c|}{$F(2.230)=6.911^{* *}$} & \multicolumn{3}{|c|}{$F(3.230)=n . s$} \\
\hline Model2 R2 & \multicolumn{3}{|c|}{0.186} & \multicolumn{3}{|c|}{0.121} & \multicolumn{3}{|c|}{0.118} & \multicolumn{3}{|c|}{0.243} \\
\hline \multirow[t]{3}{*}{ Model2 $R 2$ adjusted } & \multicolumn{3}{|c|}{0.201} & \multicolumn{3}{|c|}{0.105} & \multicolumn{3}{|c|}{0.103} & \multicolumn{3}{|c|}{0.229} \\
\hline & \multicolumn{3}{|c|}{$F(4.229)=13.086^{* *}$} & \multicolumn{3}{|c|}{$F(4.229)=7.489^{* *}$} & \multicolumn{3}{|c|}{$F(4.229)=7.695^{* *}$} & \multicolumn{3}{|c|}{$F(4.229)=18.345^{* *}$} \\
\hline & \multicolumn{3}{|c|}{ Fchange $=19.858$} & \multicolumn{3}{|c|}{ Fchange $=17.483$} & \multicolumn{3}{|c|}{ Fchange $=9.297$} & Fch & ange $=6$ & 3.743 \\
\hline
\end{tabular}

${ }^{*} p<0.05,{ }^{* *} p<0.01$.

a negative attitude toward the organization, leading to feelings of organizational cynicism and employees feel that they are being exploited by their organization [56]. In short, our results support the suggestion made by the JD-R model deriving from work psychology and by several authors: the work environment is a relevant element to explain stress reduction and well-being [13] [14] [25]. Thus, our result established a link between work psychology and environmental psychology about such a specific issue. Therefore these results underline, for further studies, that workers and managers could thus personalize their own workplace and could have an influence in promoting engagement and reduce cynicism via building and maintaining a more restorative working place. This issue, which deserves further studies, brings the attention on the perceived quality of the environment to improve people's life, in order to strive for a more positive work environment which can be able to reduce work stress [13] [14] [25]. An important result of the study proposed here is that job resources are within the control of the organization and its people, in order to foster engagement, reduce cynicism in organization and to improve psychological well-being interventions. Thus, managers have to deal with the improvement of the physical environment (that is job resource) to enhance work conditions. Future researches should explore the relationship among restorativeness, other work stressors and job resources, also considering other both physical and cultural outcomes, in different organizational contexts. However, several limitations of this study should be considered and future research could address them. First, present results are limited to a specific job resource and outcome in a specific sample, and this questions generalizability of these findings to larger working populations. Second, given the cross-sectional nature of this study, it is not possible to establish the likely direction of relationships, and the presented correlational evidence does not necessarily reflect causality. Moreover, to understand if the restorative environment's effect is maintained across time, longitudinal studies are needed, and there is also a need to account for other workplace stressors. Thirdly, all the variables were measured using self-reporting surveys rather than objective behaviours. The reliance on self-report instruments can lead to the common 
method bias due to some source of variance external to the measures [57]. It must be stressed, however, as suggested by Brannick, Chan, Conway, Lance, and Spector (2010) [58], in order to reduce possible sources of common method variance, the research was described to participants and their anonymity was ensured for reducing concern about social desirability. Further, valid scales with different response scales and anchors from previous research were used. Furthermore, in order to attenuate this limitation, construct validity, discriminant validity was analyzed.

\section{References}

[1] Bakker, A.B., Demerouti, E. and Verbeke, W. (2004) Using the Job Demands-Resources Model to Predict Burnout and Performance. Human Resource Management, 43, 83-104. http://dx.doi.org/10.1002/hrm.20004

[2] Hakanen, J., Bakker, A.B. and Schaufeli, W.B. (2006) Burnout and Work Engagement among Teachers. Journal of School Psychology, 43, 495-513. http://dx.doi.org/10.1016/j.jsp.2005.11.001

[3] Demerouti, E., Bakker, A.B., Nachreiner, F. and Schaufeli, W.B. (2001) The Job Demands-Resources Model of Burnout. Journal of Applied Psychology, 86, 499-512. http://dx.doi.org/10.1037/0021-9010.86.3.499

[4] Bakker, A.B. and Demerouti, E. (2007) The Job Demands-Resources Model: State of the Art. Journal of Managerial Psychology, 22, 309-328. http://dx.doi.org/10.1108/02683940710733115

[5] Lee, R.T. and Ashforth, B.E. (1996) A Meta-Analytic Examination of the Correlates of the Three Dimensions of Job Burnout. Journal of Applied Psychology, 81, 123-133. http://dx.doi.org/10.1037/0021-9010.81.2.123

[6] Halbesleben, J.R.B. and Buckley, M.R. (2004) Burnout in Organizational Life. Journal of Management, 30, 859-879. http://dx.doi.org/10.1016/j.jm.2004.06.004

[7] Doi, Y. (2005) An Epidemiologic Review on Occupational Sleep Research among Japanese Worker. Industrial Health, 43, 3-10. http://dx.doi.org/10.2486/indhealth.43.3

[8] Crawford, E.R., LePine, J.A. and Rich, B.L. (2010) Linking Job Demands and Resources to Employee Engagement and Burnout: A Theoretical Extension and Meta-Analytic Test. Journal of Applied Psychology, 95, 834-848. http://dx.doi.org/10.1037/a0019364

[9] Nahrgang, J.D., Morgeson, F.P. and Hofmann, D.A. (2011) Safety at Work: A Meta-Analytic Investigation of the Link between Job Demands, Job Resources, Burnout, Engagement, and Safety Outcomes. Journal of Applied Psychology, 96, 71-94. http://dx.doi.org/10.1037/a0021484

[10] Hartig, T. (2004) Restorative Environments. In: Spielberger, C., Ed., Encyclopedia of Applied Psychology, Academic Press, San Diego, 273-279. http://dx.doi.org/10.1016/B0-12-657410-3/00821-7

[11] Kaplan, R. (1993) The Role of Nature in the Context of the Workplace. Landscape and Urban Planning, 26, $193-201$. http://dx.doi.org/10.1016/0169-2046(93)90016-7

[12] Kaplan, R. and Kaplan, S. (1989) The Experience of Nature: A Psychological Perspective. Cambridge University Press, New York.

[13] Kaplan, S. (1995) The Restorative Benefits of Nature: Toward an Integrative Framework. Journal of Environmental Psychology, 15, 169-182. http://dx.doi.org/10.1016/0272-4944(95)90001-2

[14] Kaplan, S. (2001) Meditation, Restoration, and the Management of Mental Fatigue. Environment and Behavior, 33, 480-506. http://dx.doi.org/10.1177/00139160121973106

[15] Ulrich, R.S. (1983) Aesthetic and Affective Response to Natural Environments. In: Altman, I. and Wohlwill, J.F., Eds., Human Behavior and the Natural Environment, Plenum, New York, 85-125. http://dx.doi.org/10.1007/978-1-4613-3539-9_4

[16] Ulrich, R.S., Simons, R.F., Losito, B.D., Fiorito, E., Miles, M.A. and Zelson, M. (1991) Stress Recovery during Exposure to Natural and Urban Environments. Journal of Environmental Psychology, 11, 201-230. http://dx.doi.org/10.1016/S0272-4944(05)80184-7

[17] Dean, J.W., Brandes, P. and Dharwadkar, R. (1998) Organizational Cynicism. Academy of Management Review, 23, 341-352.

[18] Maslach, C., Schaufeli, W.B. and Leiter, M.P. (2001) Job Burnout. Annual Review of Psychology, 52, 397-422. http://dx.doi.org/10.1146/annurev.psych.52.1.397

[19] Bellini, D., Fornara, F. and Bonaiuto (2015) The Case of Mediating Role of Work engagement. Psyechology, 6, 252286.

[20] Kaplan, S. and Talbot, J.F. (1983) Psychological Benefits of a Wilderness Experience. In: Altman, I. and Wohlwil, J.F., Eds., Behavior and the Natural Environment, Plenum, New York, 163-203.

http://dx.doi.org/10.1007/978-1-4613-3539-9_6 
[21] Cohen, S. and Spacapan, S. (1978) The After Effects of Stress: An Attentional Interpretation. Environmental Psychology and Nonverbal Behavior, 3, 43-57. http://dx.doi.org/10.1007/BF01114531

[22] James, W. (1892) Psychology. Henry Holt and Company, New York.

[23] Steg, L., Van den Berg, A.E. and de Groot, J.I.M. (2012) Environmental Psychology. An Introduction. British Psychological Society and John Wiley \& Sons Ltd., London.

[24] Hartig, T., van den Berg, A., Hagerhall, C., Tomalek, M., Bauer, N., Hansmann, R., Ojala, A., Syngollitou, E., Carrue, G., van Herzele, A., Bell, S., Podesta, M.T.C. and Waaseth, G. (2011) Health Benefits of Nature Experience: Psychological, Social and Cultural Processes. In: Nilsson, K., Ed., Forests, Trees and Human Health, Springer, New York, 127-167. http://dx.doi.org/10.1007/978-90-481-9806-1_5

[25] Hartig, T., Evans, G.W., Jamner, L.D., Davis, D.S. and Gärling, T. (2003) Tracking Restoration in Natural and Urban Field Settings. Journal of Environmental Psychology, 23, 109-123. http://dx.doi.org/10.1016/S0272-4944(02)00109-3

[26] Shin, W.S. (2007) The Influence of Forest View through a Window on Job Satisfaction and Job Stress. Scandinavian Journal of Forest Research, 22, 248-253. http://dx.doi.org/10.1080/02827580701262733

[27] Bommer, W.H., Rich, G.A. and Rubin, R.S. (2005) Changing Attitudes about Change: Longitudinal Effects of Transformational Leader Behaviors on Employee Cynicism about Organizational Change. Journal of Organizational Behavior, 26, 733-753. http://dx.doi.org/10.1002/job.342

[28] Johnson, J. L. and O’Leary-Kelly, A.M. (2003) The Effects of Psychological Contract Breach and Organizational Cynicism: Not All Social Exchange Violations Are Created Equal. Journal of Organizational Behavior, 24, 627-647. http://dx.doi.org/10.1002/job.207

[29] Maslach, C. and Leiter, M. P. (2008) Early Predictors of Job Burnout and Engagement. Journal of Applied Psychology, 93, 498-512. http://dx.doi.org/10.1037/0021-9010.93.3.498

[30] Maslach, C. and Leiter, M.P. (2005) Stress and Burnout: The Critical Research. In: Cooper, C.L., Ed., Handbook of Stress Medicine and Health, 2nd Edition, CRC Press, London, 153-170.

[31] Maslach, C. and Leiter, M.P. (1997) The Truth about Burnout. Jossey Bass, San Francisco.

[32] Chiaburu, D.S., Peng, A.C., Oh, O.-S., Banks, G.C. and Lomeli, L.C. (2013) Antecedents and Consequences of Employee Organizational Cynicism: A Meta-Analysis. Journal of Vocational Behaviour, 83, 181-197. http://dx.doi.org/10.1016/j.jvb.2013.03.007

[33] Schaufeli, W.B., Salanova, M., González-Romá, V. and Bakker, A.B. (2002) The Measurement of Engagement and Burnout: A Confirmative Analytic Approach. Journal of Happiness Studies, 3, 71-92. http://dx.doi.org/10.1023/A:1015630930326

[34] Schaufeli, W.B. and Bakker, A.B. (2004) Job Demands, Job Resources and Their Relationship with Burnout and Engagement: A Multi-Sample Study. Journal of Organizational Behavior, 25, 293-315. http://dx.doi.org/10.1002/job.248

[35] Saks, A.M. (2006) Antecedents and Consequences of Employee Engagement. Journal of Managerial Psychology, 21, 600-619. http://dx.doi.org/10.1108/02683940610690169

[36] Britt, T.W., Castro, C.A. and Adler, A.B. (2005) Self-Engagement, Stressors, and Health: A Longitudinal Study. Personality and Social Psychology Bulletin, 31, 1475-1486. http://dx.doi.org/10.1177/0146167205276525

[37] Hackman, J.R. and Oldham, G.R. (1980) Work Redesign. Addison-Wesley, Reading.

[38] Bakker, A.B., Demerouti, E. and Schaufeli, W.B. (2003) Dual Processes at Work in a Call Centre: An Application of the Job Demands-Resources Model. European Journal of Work and Organizational Psychology, 12, 393-417. http://dx.doi.org/10.1080/13594320344000165

[39] Bakker, A.B. and Demerouti, E. (2008) Towards a Model of Work Engagement. Career Development International, 13, 209-223. http://dx.doi.org/10.1108/13620430810870476

[40] Schaufeli, W.B., Bakker, A.B. and Van Rhenen, W. (2009) How Changes in Job Demands and Job Resources Predict Burnout, Work Engagement, and Sickness Absenteeism. Journal of Organizational Behavior, 30, 893-917. http://dx.doi.org/10.1002/job.595

[41] Hobfoll, S.E. (1998) Stress, Culture, and Community: The Psychology and Physiology of Stress. Plenum, New York. http://dx.doi.org/10.1007/978-1-4899-0115-6

[42] Hobfoll, S.E. (2001) The Influence of Culture, Community, and the Nested-Self in the Stress Process: Advancing Conservation of Resources Theory. Applied Psychology: An International Review, 50, 337-370. http://dx.doi.org/10.1111/1464-0597.00062

[43] Bakker, A.B., Demerouti, E., de Boer, E. and Schaufeli, W. (2003) Job Demands and Job Resources as Predictors of Absence Duration and Frequency. Journal of Vocational Behavior, 62, 341-356. http://dx.doi.org/10.1016/S0001-8791(02)00030-1 
[44] Evans, G.W. and Stecker R. (2004) Motivational Consequences of Environmental Stress. Journal of Environmental Psychology, 24, 143-165. http://dx.doi.org/10.1016/S0272-4944(03)00076-8

[45] Balducci, C., Fraccaroli, F. and Schaufeli, W.B. (2010) Psychometric Properties of the Italian Version of the Utrecht Work Engagement Scale (UWES-9). A Cross-Cultural Analysis. European Journal of Psychological Assessment, 26, 144-150. http://dx.doi.org/10.1027/1015-5759/a000020

[46] Brandes, P., Dharwadkar, R. and Dean Jr., J.W. (1999) Does Organizational Cynicism Matter? Employee and Supervisior Perspectives on Work Outcomes. The 36th Annual Meeting of the Eastern Academy of Management, Philadelphia, 1-33.

[47] Bobbio, A., Manganelli Rattazzi, A.M. and Spadaro, S. (2006) Organizational Cynicism. Contribution to the Validation of the Italian Version of Brandes, Dhanvadkar \& Dean’s Scale. Testing Psicometria Metodologia, 13, 5-23.

[48] Hartig, T., Korpela, K., Evans, T.P. and Gärling, T. (1996) Validation of a Measure of Perceived Environmental Restorativeness. Göteborg Psychological Reports, 26, 1-64.

[49] Pasini, M., Berto, R., Scopelliti, M. and Carrus, G. (2009) Measuring the Restorative Value of the Environment: Contribution to the Validation of the Italian Version of the Perceived Restorativeness Scale. Bollettino di Psicologia Applicata, 257, 3-11.

[50] Arbuckle, J.L. (1997) AMOS Users’ Guide. Version 3.6, Smallwaters Corporation, Chicago.

[51] Bagozzi, R.P., Yi, Y. and Phillips, L.W. (1991) Assessing Construct Validity in Organizational Research. Administrative Science Quarterly, 36, 421-458. http://dx.doi.org/10.2307/2393203

[52] Stevens, J.S. (2009) Applied Multivariate Statistics for the Social Sciences. Routledge, New York.

[53] Cousineau, D. and Chartier, S. (2010) Outliers Detection and Treatment: A Review. International Journal of Psychological Research, 3, 58-67.

[54] Tabachnick, B.G. and Fidell, L.S. (2012) Using Multivariate Statistics. 6h Edition, Person Education, Boston.

[55] Ulrich, R.S. (1984) View through a Window May Influence Recovery from Surgery. Science, 224, 420-421. http://dx.doi.org/10.1126/science.6143402

[56] Banks, G.C., Whelpley, C.E., Oh, I.-S. and Shin, K. (2012) (How) Are Emotionally Exhausted Employees Harmful? International Journal of Stress Management, 19, 198-216. http://dx.doi.org/10.1037/a0029249

[57] Podsakoff, P.M., Mackenzie, S.B., Lee, J.Y. and Podsakoff, N.P. (2003) Common Method Biases in Behavioral Research: A Critical Review of the Literature and Recommended Remedies. Journal of Applied Psychology, 88, 879-903. http://dx.doi.org/10.1037/0021-9010.88.5.879

[58] Brannick, M.T., Chan, D., Conway, J.M., Lance, C.E. and Spector, P.E. (2010) What Is Method Variance and How Can We Cope with It? A Panel Discussion. Organizational Research Methods, 13, 407-420. http://dx.doi.org/10.1177/1094428109360993 


\section{Appendix 1}

Work Engagement results were based on the Schaufeli et al., 2002 version of Utrecht Work Engagement Scale (UWES). Respondents rated their level of agreement with the survey statements on a 7-point Likert type scale with options from never $(=0)$ to every day $(=6)$.

1. At my work, I feel bursting with energy.

2. At my job, I feel strong and vigorous.

3. I am enthusiastic about my job.

4. My job inspires me.

5. When I get up in the morning, I feel like going to work.

6. I feel happy when I am working intensely.

7. I am proud of the work that I do.

8. I am immersed in my job.

9. I get carried away when I am working.

\section{Appendix 2}

Organizational cynicism results were based on the Brandes, et al., 1999 version of Organizational Cynicism Scale (OCS) comprising of 3 factors with 14 items Respondents rated their level of agreement with the survey statements on a 5-point Likert type scale with options from never $(=1)$ to always $(=5)$.

\section{Cognitive component}

1. I believe that my company's says one thing and does another.

2. My organization's policies, goals, and practices seem to have little in common.

3. When my company says its going to do something, I wonder if it will really happen.

4. My organization expects one thing of its employees, but it rewards another.

\section{Emotional component}

5. I see little similarity between what my organization says it will do and what it actually does.

6. How often do you experience irritation when you think about your company?

7. How often do you experience irritation when you think about your company?

8. How often do you experience tension when you think about your company?

9. How often do you experience anxiety when you think about your company?

\section{Behavioral component}

10. I complain about things happen at my organization to friends outside the organization.

11. I Exchange "knowing” glances with co-workers.

12. I often talk to others about the way things are run at my company.

13. I criticize my organization's practices and policies with others.

14. I find myself mocking my company’s slogan and initiatives.

\section{Appendix 3}

Perceived restoration results were based on the Hartig et al., 1996 original version of the perceived restorativeness scale comprising of 4 factors with 16 items. Participants made their responses using a 7-point Likert scale to indicate their experience of the environment ( $0=$ strongly disagree; $6=$ strongly agree).

\section{Being away}

1. It is an escape experience.

2. Spending time here gives me a good break from my day-to-day routine.

\section{Coherence}

1. There is too much going on.

2. It is a confusing place.

3. There is a great deal of distraction.

4. It is chaotic here.

\section{Fascination}

1. The setting has fascinating qualities.

2. My attention is drawn to many interesting things.

3. I would like to get to know this place better. 
4. There is much to explore and discover here.

5. I would like to spend more time looking at the surroundings.

\section{Compatibility}

1. I can do things I like here.

2. I have a sense that I belong here.

3. I have a sense of oneness with this setting.

4. Being here suits my personality.

5. I could find ways to enjoy myself in a place like this. 